Schram, M.T., Frijters, D., Lisdonk, E.H. van de, Ploemacher, J., Craen, A.J.M. de, Waal, M.W.M. de, Rooij, F.J. van, Heeringa, J., Hofman, A., Deeg, D.J.H., Schellevis, F.G. Setting and registry characteristics affect the prevalence and nature of multimorbidity in the elderly. Journal of Clinical Epidemiology: 2008, 61(11), 1104-1112

\begin{tabular}{|l|l|}
\hline $\begin{array}{l}\text { Postprint } \\
\text { Version }\end{array}$ & 1.0 \\
\hline $\begin{array}{l}\text { Journal website } \\
\text { Pubmed link }\end{array}$ & $\underline{\text { http://dx.doi.org/10.1016/j.jclinepi.2007.11.021 }}$ \\
\hline DOI & $\underline{\text { http://www.ncbi.nlm.nih.gov/pubmed/18538993 }}$ \\
\hline This is a NIVEL certified Post Print, more info at http://www.nivel.eu
\end{tabular}

\title{
Setting and registry characteristics affect the prevalence and nature of multimorbidity in the elderly
}

MiRANDA T. SCHRAM ${ }^{A}$, DiNNUS FRIJTERS ${ }^{A}$, ELOY H. VAN DE LISDONK ${ }^{\mathrm{B}}$, JANNEKE PLOEMACHER $^{\mathrm{C}}$, ANTON J.M. DE CRAEN ${ }^{\mathrm{D}}$, MARGOT W.M. DE WAAL ${ }^{\mathrm{E}}$, FRANK J. VAN ROOIJ ${ }^{\mathrm{F}}$, JAN HEERINGA ${ }^{\mathrm{F}}$, ALBERT HOFMAN ${ }^{\mathrm{F}}$, DORLY J.H. DEEG ${ }^{\mathrm{A}}$, ${ }^{*}$, FRANCOIS G. SCHELLEVIS ${ }^{\mathrm{A}, \mathrm{G}}$

\author{
${ }^{a}$ Extramural Medicine (EMGO institute), VU University Medical Center, Amsterdam \\ ${ }^{\mathrm{b}}$ Department of General Practice, Radboud University Nijmegen Medical Center, Nijmegen \\ 'Statistics Netherlands, Voorburg \\ ${ }^{\mathrm{d}}$ Department of Gerontology and Geriatrics, Leiden University Medical Centre, Leiden \\ ${ }^{\mathrm{e}}$ Department of Public Health and Primary Care, Leiden University Medical Center, Leiden \\ ${ }^{\mathrm{f}}$ Department of Epidemiology and Biostatistics, Erasmus MC, Rotterdam \\ ${ }^{\mathrm{g}}$ Netherlands Institute for Health Services Research (NIVEL), Utrecht, the Netherlands \\ Accepted 30 November 2007
}

\begin{abstract}
Objective: The aim of the study was to investigate how settings and registry characteristics affect the prevalence and nature of multimorbidity in elderly individuals.

Study Design and Setting: We used data from three population-based studies, two general practitioner registries, one hospital discharge register, and one nursing home registry to estimate the prevalence of multimorbidity. Individuals aged 55 years and over were included.

Results: Multimorbidity was most prevalent in nursing homes (82\%), followed by the general population and general practitioner registries (56\%e72\%) and the hospital setting (22\%). There were large differences in the nature of multimorbidity between settings. Combinations of hypertension, heart disease, and osteoarthritis were dominant in the population-based setting, whereas hypertension in combination with osteoarthritis, obesity, disorders of lipid metabolism, and diabetes dominated in the general practitioner setting. In the hospital setting, combinations of heart diseases had the highest prevalence. Combinations of dementia, hypertension, and stroke were dominant within the nursing home setting.
\end{abstract}


Schram, M.T., Frijters, D., Lisdonk, E.H. van de, Ploemacher, J., Craen, A.J.M. de, Waal, M.W.M. de, Rooij, F.J. van, Heeringa, J., Hofman, A., Deeg, D.J.H., Schellevis, F.G. Setting and registry characteristics affect the prevalence and nature of multimorbidity in the elderly. Journal of Clinical Epidemiology: 2008, 61(11), 1104-1112

Conclusion: This study shows that setting and registry characteristics have an important influence on the outcome of multimorbidity studies. We recommend provision of at least information about the setting, the (list of) conditions included, the data collection method, and the time frame used, when reporting about the size and nature of multimorbidity. _ 2008 Elsevier Inc. All rights reserved.

\section{INTRODUCTION}

Multimorbidity is a common phenomenon in elderly subjects. It refers to the presence of more than one, usually chronic, health problem in one person. According to literature, the prevalence of multimorbidity in the general population and in family medicine surveys ranges from 35\% to 99\% in individuals over 60 years of age, and increases with age [1e3]. Due to the aging populations in Western societies the prevalence of multimorbidity is expected to rise in the coming years. Up to now, multimorbidity has been investigated in diverse settings, ranging from general populations to institutionalized populations and using various methods of data collection. It is plausible that a general population-based setting results in a lower prevalence of multimorbidity than for instance a nursing home setting. Differences in prevalence between a population-based and general practitioner (GP) setting are more difficult to predict. It is important to know how differences in setting influence the prevalence of multimorbidity because these figures may be used for health care planning. Furthermore, the total disease burden of populations may be estimated from multimorbidity analyses. In addition to setting, registries that are used for multimorbidity estimates may differ in registry characteristics such as the focus on specific chronic diseases, the number of disease registered, the diagnostic method used. This may influence the size and nature of multimorbidity. Currently, the effect of setting and registry characteristics on the size and nature of multimorbidity is unknown. We hypothesized that the prevalence of multimorbidity is largely dependent on the setting and registry characteristics. Therefore, we investigated the effect of setting and registry characteristics on the prevalence and nature of multimorbidity in individuals over 55 years of age. To evaluate the effect of setting and other differences between registries on the nature of multimorbidity, we made the focus comparable by selecting one disease (diabetes) as index disease and compared its comorbidity between settings.

\section{METHODS}

\subsection{Multimorbidity}

Multimorbidity was defined as the presence of at least two chronic conditions in one person. Comorbidity was defined as the presence of one index disease and at least one other chronic condition in one person. A chronic condition was defined as lasting 12 months or longer and meeting one or both of the following criteria: (a) it places limitations on self-care, independent living, or social interactions; (b) it results in the need for ongoing intervention with medical products, services, and special equipment. We used the Chronic Condition Indicator [4] to identify the chronicity of conditions. This indicator was constructed by a panel of five internists whom individually judged 578 three-digit International Classification of Diseases (ICD)-9-CM codes to be chronic or not. Out of the 578 codes, a total of 185 conditions were classified as being chronic. The conditions measured in all registries were already ICD-9 coded, or recoded into ICD-9 codes. We used the most recently collected information (1997 or more recent) in the different registries to estimate an up-to-date 
Schram, M.T., Frijters, D., Lisdonk, E.H. van de, Ploemacher, J., Craen, A.J.M. de, Waal, M.W.M. de, Rooij, F.J. van, Heeringa, J., Hofman, A., Deeg, D.J.H., Schellevis, F.G. Setting and registry characteristics affect the prevalence and nature of multimorbidity in the elderly. Journal of Clinical Epidemiology: 2008, 61(11), 1104-1112

prevalence of multimorbidity. We defined elderly as individuals over 55 years of age. Our aim to use the most recent data available resulted in different age limits in the population studies, because these studies applied different age limits

\section{[TABLE 1]}

\subsection{Study populations}

This study used data from population-based studies (the Longitudinal Aging Study Amsterdam [LASA], the Rotterdam Study, and the Leiden 85-plus Study), GP registries (the Continuous Morbidity Registry Nijmegen [CMR Nijmegen] and the Registration Network University General Practitioners Leiden and surroundings [RNGP]), the Dutch National Hospital Discharge Register (the ' Landelijke Medische Registratie’'[LMR]), and a nursing home registry (the VU University Medical Center Resident Assessment Instrument database [RAI]). Table 1 gives an overview of the registry characteristics.

\subsection{Population-based settings}

\subsubsection{LASA}

The LASA is a longitudinal study on predictors and consequences of changes in physical, cognitive, emotional, and social functioning in the population (birth years 1908e1937) [5]. In 1992, a sample of people aged 55e85 years, stratified for age, sex, and expected attrition due to mortality at midterm of LASA (after 5 years) in each age group, was drawn from the population registries of 11 municipalities in three culturally distinct geographical areas in the west, northeast, and south of the Netherlands. Each area consisted of one middle to large-size city and two or more rural municipalities that border on the city. The initial LASA sample consisted of 3,107 participants at baseline (1992e1993, response rate 62.3\%). Follow-up examinations were conducted in1995, 1998, and 2001e2002. In 2002, a new cohort (birth years 1938e1947) was added using the same sampling frame as the original cohort. This second cohort included 1,002 individuals [6]. The medical history of participants was obtained from self-reports as well as from the GP; both were used to determine multimorbidity. All subjects gave informed consent and were interviewed and tested at home. We used data from the third follow-up examination of the first cohort (n51,691) and the first examination of the second cohort (n51,002, age range 55e94) to estimate the prevalence of multimorbidity. Information on the following chronic conditions was collected: asthma/chronic obstructive pulmonary disease (COPD), cardiac disease, peripheral artery disease, diabetes, stroke, rheumatoid arthritis/osteoarthritis, malignancies, and hypertension. Depression and anxiety disorders were diagnosed according to the DSM IV criteria.

\subsubsection{The Rotterdam Study}

The Rotterdam Study is a prospective population-based cohort study on determinants of chronic disabling diseases in the elderly [7] The study was conducted among 7,983 subjects $>55$ years of age living in Ommoord, a suburb of Rotterdam, the Netherlands (response rate 78\%). Both at baseline (1990e1993) and three follow-up examinations (1993e1994, 1997e1999, and 2002e2004), all participants were interviewed at home and underwent an extensive physical examination at the research center. We used data from the third follow-up examination (2002e2004, individuals were then aged 65 years and over) to assess the prevalence of multimorbidity in the general population. Information on the following chronic conditions was collected: malignancies (GP information only), diabetes, obesity (body mass index $>30$ ), depression, anxiety, Parkinson's disease, eye diseases, hypertension, myocardial infarction, angina pectoris, atherosclerosis, underwent percutaneous transluminal coronary angioplasty and/or coronary artery bypass grafting, transient ischemic attack, stroke, and 
Schram, M.T., Frijters, D., Lisdonk, E.H. van de, Ploemacher, J., Craen, A.J.M. de, Waal, M.W.M. de, Rooij, F.J. van, Heeringa, J., Hofman, A., Deeg, D.J.H., Schellevis, F.G. Setting and registry characteristics affect the prevalence and nature of multimorbidity in the elderly. Journal of Clinical Epidemiology: 2008, 61(11), 1104-1112

dementia. Atherosclerosis was defined as the presence of multiple plaques in the carotid arteries as assessed by carotid ultrasound examination. Depression and anxiety disorders were diagnosed according to the DSM IV criteria.

\subsubsection{The Leiden 85-plus Study}

The Leiden 85-plus Study is a longitudinal populationbased study of subjects living in Leiden aged 85 years at inclusion [8]. These oldest old were followed for 5 years. In total, 705 individuals were approached of whom 599 agreed to participate (response rate 85\%). Baseline data were collected between 1997 and 1999. All participants were visited at their place of residence, where face-to-face interviews were conducted. The medical history of all participants was obtained from their GP or treating nursing home physician. Data on medication were obtained from pharmacies. We used data from the baseline examination to estimate the prevalence of multimorbidity in the general population at age 85 years. Information on the following chronic conditions was collected as previously described [9]: myocardial infarction, stroke, diabetes, Parkinson's disease, dementia, osteoarthritis, COPD, malignancies, transient ischemic attack, angina pectoris, hypertension, and depression. Depression was defined as a score $>4$ on the 15-item Geriatric Depression Scale [10].

\subsection{GP settings}

\subsubsection{CMR Nijmegen}

The CMR Nijmegen started in 1971 and collects information from four general practices with 10 GPs and about 13,000 registered patients in the Nijmegen region of the Netherlands [11]. On January 1, 2005, data of 3,435 individuals aged 55 years and over were available in the database. We included those individuals with at least 10 years of registration time in the analyses $(\mathrm{n} 52,895)$ to assure a well-grounded estimate of multimorbidity. Information on all morbidity (complaints, diseases, and disorders) from patients who contact their GP was registered. Morbidity was coded according to the E-list (based on the ICD-7) and was translated into ICD-9-CM codes. Sixty-eight conditions overlapped with the 185 of the chronic disease indicator list and only those with a prevalence of over $2 \%$ were used for the analyses.

\subsubsection{RNUGP}

The RNUGP started in 1992 and collects information from four general practices with 20 GPs and about 30,000 registered patients in the Leiden region of the Netherlands from 1999 onward. On January 1, 2006, data of 7,816 individuals aged 55 years and over were available in the database. We included those individuals with at least 5 years of registration time in the analyses $(\mathrm{n} 55,610)$ to assure a well-grounded estimate of multimorbidity. Information on all morbidity (complaints, diseases, and disorders) from patients who contact their GP is registered. Morbidity was coded according to ICPC-1 and was translated to ICD-9-CM codes. Eighty-three conditions overlapped with the chronic disease indicator list and only those with a prevalence over $2 \%$ were used for the analyses.

\subsection{Hospital setting}

\subsection{1. $L M R$}

The Dutch National Hospital Discharge Register (the "Landelijke Medische Registratie', Prismant, Utrecht) collects information on each hospital admission, including daycare, from virtually all general and university hospitals and most specialty hospitals in the Netherlands. The register includes the principal diagnosis, which is determined at discharge and is in retrospect the main reason for admission. Furthermore, the register includes secondary diagnoses, date of admission and discharge, date of birth, and sex. All diagnoses were coded 
Schram, M.T., Frijters, D., Lisdonk, E.H. van de, Ploemacher, J., Craen, A.J.M. de, Waal, M.W.M. de, Rooij, F.J. van, Heeringa, J., Hofman, A., Deeg, D.J.H., Schellevis, F.G. Setting and registry characteristics affect the prevalence and nature of multimorbidity in the elderly. Journal of Clinical Epidemiology: 2008, 61(11), 1104-1112

according to the ICD-9-CM. We used data from all hospital discharges between January 2003 and December 2004 of individuals over 55 years of age to estimate the prevalence of multimorbidity $(\mathrm{n} 51,058,234)$. Only individuals who could be followed up completely during this period were included. All 185 conditions of the chronic condition indicator list were registered in the LMR. Note that registration of the principal discharge diagnosis was obligatory, whereas registration of secondary diagnoses was optional, which may affect the estimated magnitude of multimorbidity. In addition, it is likely that the registration of secondary diagnoses is focused at those relevant for the specific hospital admission and thus does not necessarily contain all secondary diagnoses of the patient.

\subsection{Nursing home setting}

\subsection{1. $R A I$}

The RAI collects data from seven nursing homes in the Netherlands (five in Amsterdam, one in Groningen, and one in Oegstgeest) on all individuals who are admitted to a nursing home. These seven nursing homes are a representative sample of all 340 Dutch nursing homes. Between January and December 2005, the seven nursing homes had 1,274 residents aged 55 years and over. All individuals underwent the RAI at admission or (at least) once per year [12], which consists of an individual assessment tool containing questions about a variety of patient characteristics such as gender, acute and chronic diseases, medication use, and therapy. Trained nurses complete the assessment and are prompted to gather information from record notes, observations, interviews (with patients and/or families) and clinicians. Information on the following chronic conditions was collected: diabetes, thyroid disease, ischemic heart disease, arrhythmias, heart failure, unspecified heart disease, peripheral vascular disease, hypertension, stroke, transient ischaemic attack, rheumatoid arthritis/osteoarthritis, dementia, eye disease, cerebral palsy, malignancies, depression, anxiety, COPD/emphysema, asthma, Parkinson's disease, epilepsy, schizophrenia, paraplegia, multiple sclerosis, renal insufficiency, and anemia. Further details about study design and the diagnosis of chronic conditions included in these analyses can be obtained from the authors.

\subsection{Comorbidity of diabetes}

To evaluate the effect of setting and registry characteristics on the nature of multimorbidity, we used diabetes as index disease and compared its comorbidity between settings. By this approach, we fixed one of the components of multimorbidity, because diabetes was assessed in all settings. Diabetes was chosen as index disease because it was the only comparable condition determined in all registries.

\section{RESULTS}

\subsection{Prevalence of multimorbidity}

The prevalence of multimorbidity ranged from $56 \%$ to $72 \%$ in the general population. The result in GP registries was highly comparable to that in the population-based studies; the prevalence of multimorbidity ranged from $56 \%$ to $66 \%$. Within the persons with multimorbidity, the combination of two conditions was most common in the populationbased setting. In the GP setting, the combination of four or more conditions was most prevalent. Due to the characteristics of the register, multimorbidity was least prevalent in the hospital setting. In nursing homes, nearly all residents suffered from chronic disease. Only $5 \%$ of this population had no chronic disease and was probably admitted to the nursing home for rehabilitation. The prevalence of multimorbidity in nursing homes was $82 \%$ 
Schram, M.T., Frijters, D., Lisdonk, E.H. van de, Ploemacher, J., Craen, A.J.M. de, Waal, M.W.M. de, Rooij, F.J. van, Heeringa, J., Hofman, A., Deeg, D.J.H., Schellevis, F.G. Setting and registry characteristics affect the prevalence and nature of multimorbidity in the elderly. Journal of Clinical Epidemiology: 2008, 61(11), 1104-1112

\section{[FIGURE 1, 2 AND 3]}

\subsection{Nature of multimorbidity}

Table 2 shows the top five of most prevalent combinations of conditions in the populationbased, the GP, the hospital, and nursing home settings. Although the nature of the combinations of conditions differed between the population-based studies, hypertension, heart disease, and osteoarthritis were common constituents of multimorbidity within this setting. The prevalence of atherosclerosis and hypertension was highest in the Rotterdam Study. In this study, atherosclerosis was defined by use of caratid ultrasound, which resulted in a high prevalence of atherosclerosis. Hypertension was the most prevalent condition in the Leiden 85-plus Study (57\%) and the second prevalent condition in LASA (37\%) and the Rotterdam Study (62\%), and therefore highly prevalent in multimorbidity estimates.

In the GP setting, again combinations with hypertension and osteoarthritis were most common. Although there were some differences in the nature of multimorbidity, the combination of hypertension with osteoarthritis, diabetes, and disorders of the lipid metabolism occurred in the top five of both registries. In the hospital setting, the combination of ischemic heart disease and other heart disease was most common. These conditions reflect the indications for admittance to the hospital. Furthermore, combinations of heart disease with hypertension and diabetes presented in the top five. In nursing homes, dementia and stroke were the most prevalent constituents of multimorbidity. These conditions also represent indications of admittance to the nursing home. In addition, combinations with hypertension and osteoarthritis presented in the top five.

When comparing the figures between settings, the highest prevalence of multimorbidity combinations was observed in the population-based setting, whereas the estimates of multimorbidity were very low $\mathrm{n}$ the hospital setting. In addition, despite the impressive prevalence of multimorbidity in nursing homes, the estimated prevalence

\subsection{Comorbidity of diabetes}

For better comparability between settings, we selected one index disease, diabetes, and compared comorbidity of this disease between settings. The prevalence of diabetes ranged from $12 \%$ to $18 \%$ in the population-based setting, from $11 \%$ to $15 \%$ in the GP setting, $5 \%$ in the hospital setting, and $18 \%$ in the nursing home setting. Table 3 shows the results of the comorbidity analyses of diabetes. Diabetes and hypertension was the most prevalent combination in both the population-based and the GP setting; the levels of prevalence varied from $6 \%$ to $13 \%$. This combination also occurred in the hospital and nursing home registries. The combination of diabetes and heart disease was also prevalent in all registries, with the highest frequency in the population-based setting. Other combinations with diabetes varied per setting, for instance, the combination with dementia and stroke was prevalent in nursing homes only, whereas the combination with disorders of lipid metabolism frequently occurred in the GP setting.

\section{[TABLE 2 AND 3]}

\section{DISCUSSION}

This study shows that setting has an important influence on the size and nature of multimorbidity. In this study, the prevalence of multimorbidity ranged from $22 \%$ to $82 \%$ in different settings. In addition, the nature of multimorbidity varied across settings. This study has several strengths. First, we investigated the prevalence of multimorbidity in a wide range of settings, including three population-based studies, two GP registries, one hospital register, and one nursing home registry. This resulted in a comprehensive overview of 
Schram, M.T., Frijters, D., Lisdonk, E.H. van de, Ploemacher, J., Craen, A.J.M. de, Waal, M.W.M. de, Rooij, F.J. van, Heeringa, J., Hofman, A., Deeg, D.J.H., Schellevis, F.G. Setting and registry characteristics affect the prevalence and nature of multimorbidity in the elderly. Journal of Clinical Epidemiology: 2008, 61(11), 1104-1112

multimorbidity. Second, we defined conditions according to the first three characters of the ICD. This approach is broader than a classification by organ system. It allows discrimination between conditions within one organ and is internationally accepted to diagnose diseases. Third, we used the same definition of chronic conditions for all settings [4]. Although the eventual selection of conditions was dependent on the information collected by the different registries, there is a large overlap of conditions between registries, especially within the GP setting. Fourth, medical records, which are considered to be the best way to collect information on medical conditions [1], were used in most settings to determine the presence of a condition, ensuring a valid diagnosis of chronic conditions. We found that combinations of more than three chronic conditions were most prevalent in the GP setting. However, when reporting the top five of multimorbidity, combinations of two conditions had the highest frequency. This suggests that the category of three or more conditions includes very diverse combinations with a corresponding low prevalence. Thus, patients with multimorbidity suffer from a large variety of conditions. The concept of multimorbidity depends on the conditions included. We used ICD codes to define chronic conditions. This choice infers that conditions like hypertension, disorders of the lipid metabolism, and obesity are included in our analyses as well, which increases the prevalence of multimorbidity, but considering these conditions as diseases is debatable. However, these conditions are strongly related to health and mortality, they require treatment, and increase the need for medical care and the risk of complications. In our opinion, it is therefore justified to include these conditions in multimorbidity analyses. The number of conditions registered strongly influences the observed extent of multimorbidity, as is shown by the high prevalence of more than three chronic conditions (23\%e32\%) in the GP setting compared to the population-based setting (15\%e24\%). One major advantage of GP registries is that the entire spectrum of morbidity as presented to GPs is included in the registry, resulting in a comprehensive overview of multimorbidity. Taken together, the observed maximum prevalence of multimorbidity of $72 \%$ in the population-based setting may still be an underestimation. The time span used to estimate multimorbidity may also affect the outcome. In the GP registries, we selected a cohort that was registered at one time point and used information from the previous 5 or 10 years in the past to estimate multimorbidity. We observed a higher prevalence of multimorbidity when using the 10-year prevalence. Therefore, we recommend the use of long follow-up periods for optimal assessment of the extent of multimorbidity. The method and quality of data collection and the focus of a study have an important effect on the size and nature of multimorbidity. The population settings used an active case-finding approach, which is even more thorough than using medical records. As a result the diseases of interest dominated the nature of multimorbidity in populationbased studies. This effect (but smaller) was still noticed when using diabetes as index disease. These analyses show that, despite fixing one component of multimorbidity, there is still variation in the nature of multimorbidity due to differences in focus and method of detection. Goals between the included registries differed largely. The population-based studies measured prevalence rates for research purposes, whereas GP registries aim at improving patient care, medical education, and performing research, the hospital register uses information for policy making and research purposes, and the nursing home registry was set up to improve medical care. Taken together, these different goals may explain some of the observed differences in nature of multimorbidity. Age is strongly related to multimorbidity. We restricted the analyses to individuals aged 55 years and over. However, the Rotterdam Study included individuals aged 65 years and over while the Leiden 85-plus Study included only 85-year olds. This may have lead to an overestimation of multimorbidity in these registries. This study had several limitations, which we will discuss per setting. In a population-based setting, selective attrition is inevitable. We preferred to use the most recent above the most complete examination to estimate multimorbidity. However, both the LASA and the Leiden 85-plus Study showed that the very healthy and the very ill refused to participate in these studies $[5,8]$. These two groups represent the two extremes of the population distribution. When 
Schram, M.T., Frijters, D., Lisdonk, E.H. van de, Ploemacher, J., Craen, A.J.M. de, Waal, M.W.M. de, Rooij, F.J. van, Heeringa, J., Hofman, A., Deeg, D.J.H., Schellevis, F.G. Setting and registry characteristics affect the prevalence and nature of multimorbidity in the elderly. Journal of Clinical Epidemiology: 2008, 61(11), 1104-1112

these extremes are both not included in a population study the mean of the distribution will not be affected. We assume that this selective nonresponse from both subgroups will be balanced, that is, that the net effect will be negligible. Therefore, the estimates presented here can be considered a good representation of the prevalence of multimorbidity in the general population. In addition, the number of conditions measured in the population-based setting was limited. This may have resulted in an underestimation of multimorbidity. It is important to realize that the GP setting reflects morbidity that is seen, recognized, and documented by medical professionals [13]. It is especially known that psychiatric morbidity was not well recognized in general practice [14,15]. Moreover, the underdiagnosis of psychiatric conditions was even more pronounced among somatically ill patients [16]. Therefore, the prevalence of comorbidity of psychiatric conditions is probably underestimated in this setting. In addition, the presentation of the patient and the diagnostic awareness of GPs for specific conditions may influence the results. The absolute prevalence of multimorbidity was substantially underestimated in the hospital setting.This underestimation originates from the data collectionmethod; registration of the principal discharge diagnosis was obligatory, whereas registration of secondary diagnoses was optional.Many hospitals did not fill in secondary diagnoses due to time restrains, leading to a considerable under registration ofmultimorbidity. In addition, it is likely that in particular secondary diagnoses that were related to the admissionwere registered; the registration of other disease within a patient was probably not complete. On the other hand, this register included over one million individuals and thus provides exact estimates ofmultimorbidity. Therefore, these data do increase our insight into the nature of multimorbidity in the hospital setting. Due to the registration of all 185 chronic conditions in the hospital setting, many combinations, which were not observed in other settings, were found. The main drawback of the nursing home registry may be the assessment by nurses rather than physicians. However, the RAI was specifically developed for assessment by nurses. These nurses were specifically trained in the skills required, thus also to recognize the conditions as present in the RAI, although some conditions may be overlooked or not recognized because of other severe morbidity or nonspecific complaints in especially the oldest residents. In summary, we have demonstrated that setting and registry characteristics have an important effect on the prevalence and nature of multimorbidity. When an index disease was used to describe comorbidity, differences between settings remained. Especially the comprehensiveness, active case finding vs. the use of medical registries, are important determinants of the prevalence of multimorbidity. In addition, the focus on specific diseases and the time span used to assess multimorbidity affect the prevalence of multimorbidity. We therefore recommend provision of at least information about the setting, the (list of) conditions included, the data source, and the time frame of the collected data, when reporting about the size and nature of multimorbidity.

\section{ACKNOWLEDGMENTS}

This study was requested and financially supported by the Health Council of the Netherlands. We thank all colleagues involved in this project: M.W. Ribbe, Extramural Medicine (EMGO institute), VU University Medical Center, Amsterdam; H. van den Hoogen and H. Bor, Department of General Practice, Radboud University Nijmegen Medical Center, Nijmegen; A. de Bruin and S.J.M. de Ree, Statistics Netherlands, Voorburg; R.G.J. Westendorp, Department of Gerontology and Geriatrics, Leiden University Medical Center, Leiden; J. Gussekloo and W.J.J. Assendelft, Department of Public Health and Primary Care, Leiden University Medical Center, Leiden. 
Schram, M.T., Frijters, D., Lisdonk, E.H. van de, Ploemacher, J., Craen, A.J.M. de, Waal, M.W.M. de, Rooij, F.J. van, Heeringa, J., Hofman, A., Deeg, D.J.H., Schellevis, F.G. Setting and registry characteristics affect the prevalence and nature of multimorbidity in the elderly. Journal of Clinical Epidemiology: 2008, 61(11), 1104-1112

\section{REFERENCES}

[1] Fortin M, Bravo G, Hudon C, Vanasse A, Lapointe L. Prevalence of multimorbidity among adults seen in family practice. Ann Fam Med 2005;3:223e8.

[2] Schellevis FG, van der Velden J, van de Lisdonk E, van Eijk JThM, van Weel C. Comorbidity of chronic diseases in general practise. J Clin Epidemiol 1993;46:469e73.

[3] van den Akker M, Buntinx F, Metsemakers JF, Roos S, Knottnerus JA. Multimorbidity in general practice: prevalence, incidence, and determinants of co-occuring chronic and recurrent diseases. J Clin Epidemiol 1998;51:367e75.

[4] Hwang W, Weller W, Ireys H, Anderson G. Out-of-pocket medical spending for care of chronic conditions. Health Aff (Millwood) 2001;20(6):267e78.

[5] Deeg DJ, van Tilburg T, Smit JH, de Leeuw ED. Attrition in the Longitudinal Aging Study Amsterdam. The effect of differential inclusion in side studies. J Clin Epidemiol 2002;55:319e28.

[6] Visser M, Pluijm SM, van der Horst MH, Poppelaars JL, Deeg DJ. Lifestyle of Dutch people aged 55-64 years less healthy in 2002/'03 than in 1992/'93. Ned Tijdschr Geneeskd 2005;149(53):2973e8.

[7] Hofman A, Grobbee DE, de Jong PT, van den Ouweland FA. Determinants of disease and disability in the elderly: the Rotterdam Elderly Study. Eur J Epidemiol 1991;7:403e22.

[8] der Wiel AB, Van Exel E, de Craen AJ, Gussekloo J, Lagaay AM, Knook DL, et al. A high response is not essential to prevent selection bias: results from the Leiden 85-plus study. J Clin Epidemiol 2002;55:1119e25.

[9] Bootsma-van der Wiel A, de Craen AJ, Van Exel E, Macfarlane PW, Gussekloo J, Westendorp RG. Association between chronic diseases and disability in elderly subjects with low and high income: the Leiden 85-plus Study. Eur J Public Health 2005;15:494e7.

[10] Vinkers DJ, Gussekloo J, Stek ML, Westendorp RG, van der Mast RC. The 15-item Geriatric Depression Scale (GDS-15) detects changes in depressive symptoms after a major negative life event. The Leiden 85-plus Study. Int J Geriatr Psychiatry 2004;19:80e4.

[11] van de Lisdonk EH, van den Bosch WJHM, Huygen FJA, Largo-Janssen ALM. Ziekten in de Huisartsenpraktijk. [Diseases in general practise.] Elsevier/Bunge: Maarssen; 2003.

[12] Achterberg W, Pot AM, van Campen C, Ribbe M. Resident Assessment Instrument (RAl): a review of international research on the psychometric qualities and effects of implementation in nursing homes. Tijdschr Gerontol Geriatr 1999;30(6):264e70.

[13] Gijsen R, Poos MJ. Using registries in general practice to estimate countrywidemorbidity in TheNetherlands. PublicHealth 2006;120:923e36.

[14] Nuyen J, Schellevis FG, Satariano WA, Spreeuwenberg PM, Birkner MD, van den Bos $\mathrm{GA}$, et al. Comorbidity was associated with neurologic and psychiatric diseases: a general practice-based controlled study. J Clin Epidemiol 2006;59:1274e84.

[15] Van Exel E, Stek ML, Deeg DJ, Beekman AT. The implication of selection bias in clinical studies of late life depression: an empirical approach. Int J Geriatr Psychiatry 2000;15:488e92.

[16] Nuyen J, Volkers AC, Verhaak PF, Schellevis FG, Groenewegen PP, van den Bos GA. Accuracy of diagnosing depression in primary care: the impact of chronic somatic and psychiatric co-morbidity. Psychol Med 2005;35:1185e95. 
Schram, M.T., Frijters, D., Lisdonk, E.H. van de, Ploemacher, J., Craen, A.J.M. de, Waal, M.W.M. de, Rooij, F.J. van, Heeringa, J., Hofman, A., Deeg, D.J.H., Schellevis, F.G. Setting and registry characteristics affect the prevalence and nature of multimorbidity in the elderly. Journal of Clinical Epidemiology: 2008, 61(11), 1104-1112

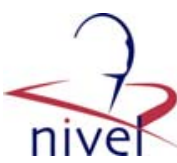

TABLES AND FIGURES

Table 1

Characteristics of the studied registries

\begin{tabular}{|c|c|c|c|c|c|c|c|}
\hline & \multicolumn{3}{|c|}{ Population-based registries } & \multicolumn{2}{|l|}{ GP registries } & \multirow{2}{*}{$\frac{\text { Hospital register }}{\text { LMR }}$} & \multirow{2}{*}{$\begin{array}{l}\text { Nursing home registry } \\
\text { RAI }\end{array}$} \\
\hline & LASA & Rotterdam Study & Leiden $85+$ Study & CMR Nijmegen & RNUGP & & \\
\hline Setting & General population & General population & General population & GP & GP & Hospital & Nursing home \\
\hline Population size & 2,463 & 3,550 & 599 & 2,895 & 5,610 & $1,058,234$ & 1,274 \\
\hline Female sex & $56 \%$ & $60 \%$ & $67 \%$ & $53 \%$ & $52 \%$ & $54 \%$ & $70 \%$ \\
\hline Age range & $55-94$ & $65-99$ & 85 & 55 and over & 55 and over & 55 and over & 55 and over \\
\hline Recruitment & Invited to participate & Invited to participate & Invited to participate & Registered at GP & Registered at GP & Admitted to the hospital & Admitted to the nursing home \\
\hline Measurement period & 2001 & 2002 & 1997 & 2005 & 2006 & $2003-2004$ & 2005 \\
\hline Time within registry & 9 years (first cohort) & 11 years & - & 10 years & 5 years & - & - \\
\hline Coverage of disease list & 10 conditions & 14 conditions & 12 conditions & 72 conditions & 83 conditions & all 185 conditions & 26 conditions \\
\hline Diagnostic validity & $\begin{array}{l}\text { - Self report } \\
\text { - GP interview }\end{array}$ & $\begin{array}{l}\text { - Self report } \\
\text { - GP interview } \\
\text { - Medical records } \\
\text { - Pharmacy records } \\
\text { - Measurements }\end{array}$ & $\begin{array}{l}\text { - GP interview } \\
\text { - Medical rocords } \\
\text { - Pharmacy records } \\
\text { - Measurements }\end{array}$ & - GP diagnosis & - GP diagnosis & - Specialist diagnosis & $\begin{array}{l}\text { - Nurses diagnosis using } \\
\text { the Resident Assessment } \\
\text { Instrument }\end{array}$ \\
\hline
\end{tabular}

Abbreviations: LASA, Longitudinal Aging Study Amsterdam; CMR Nijmegen, Continuous Morbidity Registry Nijmegen; RNUGP, Regional Network University General Practitioners Leiden and surroundings; LMR, Dutch National Medical Registry (Landelijke Medische Registratie); RAI, the VU University Medical Center Resident Assessment Instrument database.

Prevalence of multimorbidity in population-based and GP settings

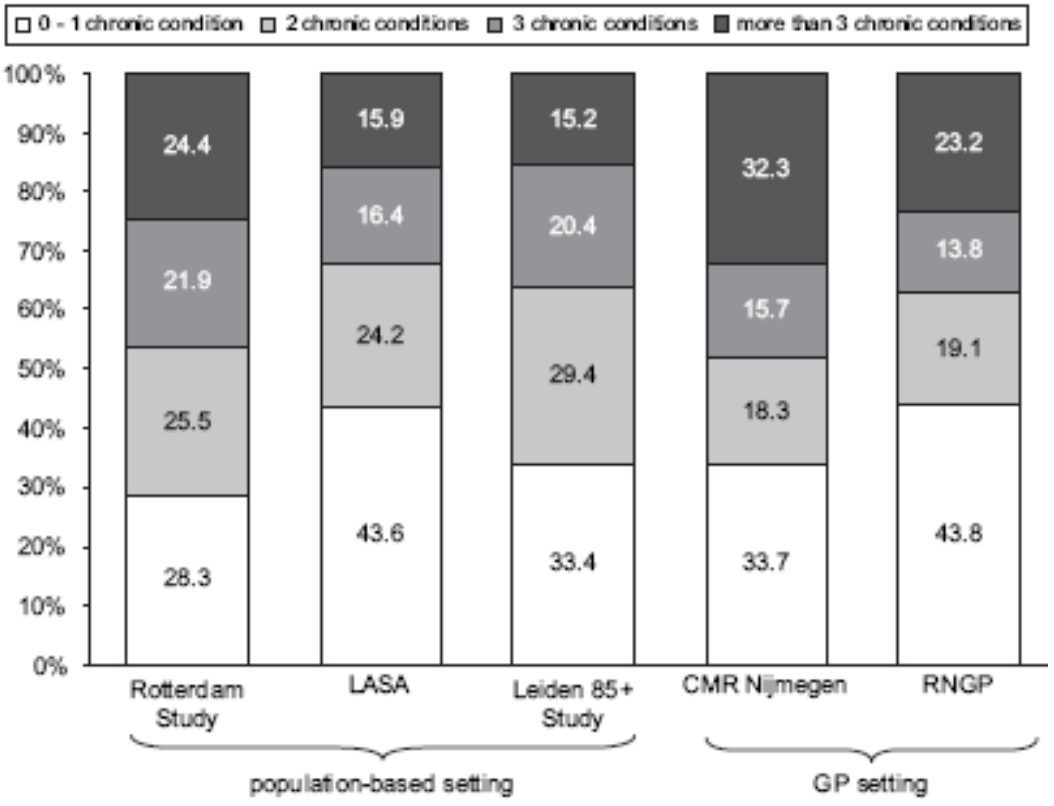

Fig. 1. Prevalence of multimorbidity in population-based and GP settings. 
Schram, M.T., Frijters, D., Lisdonk, E.H. van de, Ploemacher, J., Craen, A.J.M. de, Waal, M.W.M. de, Rooij, F.J. van, Heeringa, J., Hofman, A., Deeg, D.J.H., Schellevis, F.G. Setting and registry characteristics affect the prevalence and nature of multimorbidity in the elderly. Journal of Clinical Epidemiology: 2008, 61(11), 1104-1112
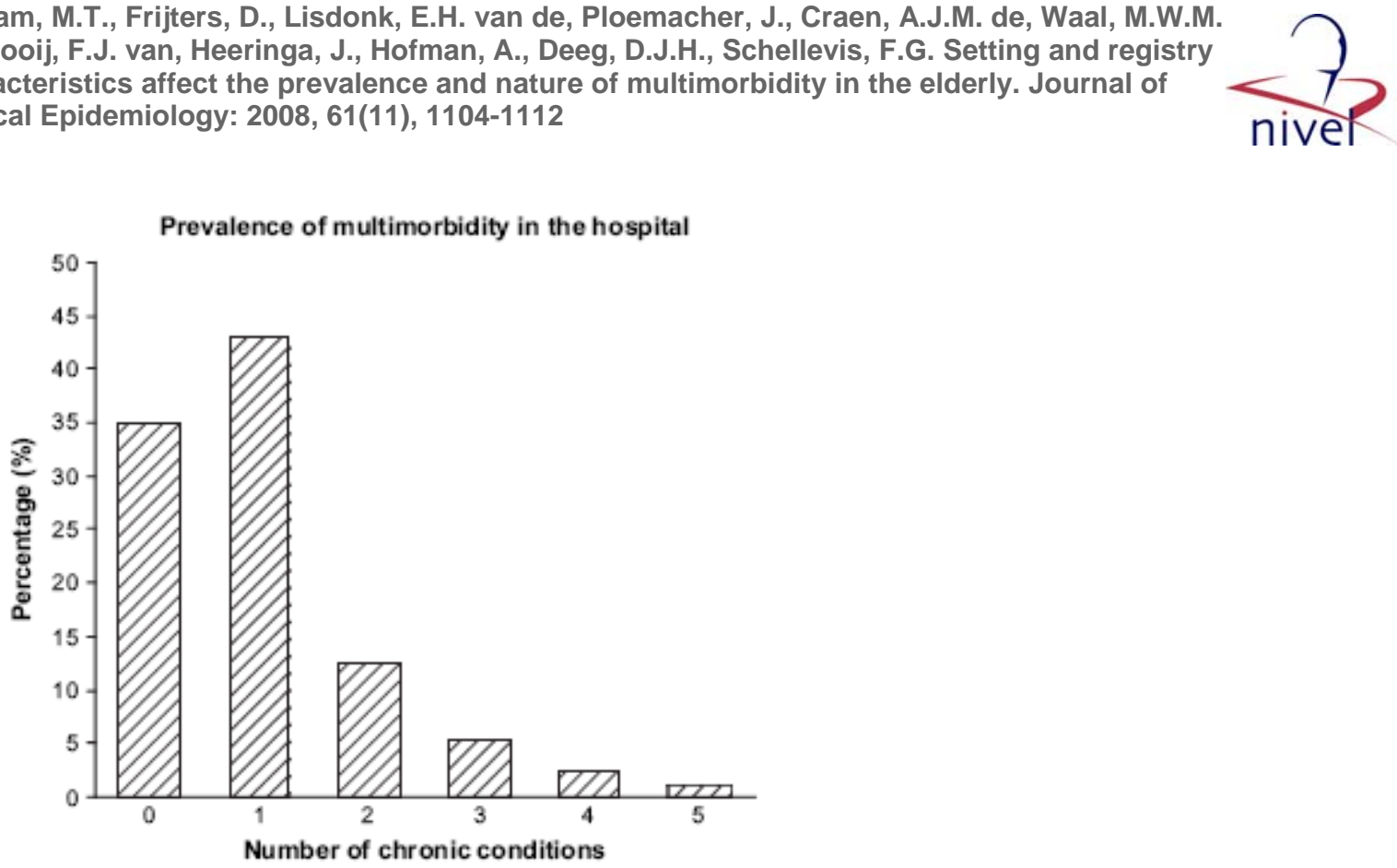

Fig. 2. The prevalence of multimorbidity in the hospital.

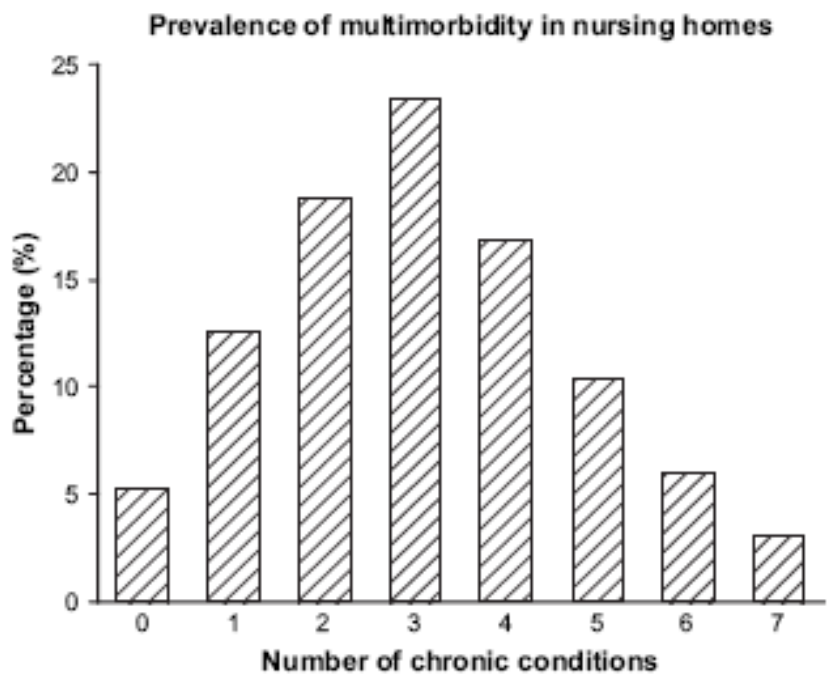

Fig. 3. The prevalence of multimorbidity in nursing homes. 
Schram, M.T., Frijters, D., Lisdonk, E.H. van de, Ploemacher, J., Craen, A.J.M. de, Waal, M.W.M. de, Rooij, F.J. van, Heeringa, J., Hofman, A., Deeg, D.J.H., Schellevis, F.G. Setting and registry characteristics affect the prevalence and nature of multimorbidity in the elderly. Journal of Clinical Epidemiology: 2008, 61(11), 1104-1112

Table 2

Top five multimorbidities in all settings

\begin{tabular}{|c|c|c|}
\hline & Combination of diseases & Prevalence $(\%)$ \\
\hline \multicolumn{3}{|c|}{ Population-based setting } \\
\hline \multicolumn{3}{|c|}{ LASA } \\
\hline 1 & Hypertension (37.1) and osteoarthritis (50.9) & 20.1 \\
\hline 2 & Ischemic heart disease (29.6) and osteoarthritis & 17.5 \\
\hline 3 & Ischemic heart disease and hypertension & 14.9 \\
\hline 4 & Osteoarthritis and malignancies (18.3) & 10.0 \\
\hline 5 & Osteoarthritis and COPD (16.2) & 9.5 \\
\hline \multicolumn{3}{|c|}{ Rotterdam Study } \\
\hline 1 & Atherosclerosis (63.3) and hypertension (61.8) & 42.2 \\
\hline 2 & Hypertension and obesity (18.8) & 14.7 \\
\hline 3 & Atherosclerosis and obesity & 13.2 \\
\hline 4 & Hypertension and diabetes (17.7) & 12.0 \\
\hline 5 & Atherosclerosis and diabetes & 10.4 \\
\hline \multicolumn{3}{|c|}{ Leiden 85-plus Study } \\
\hline 1 & Hypertension (56.9) and osteoarthritis (32.5) & 18.7 \\
\hline 2 & Hypertension and angina poctoris (18.4) & 13.1 \\
\hline 3 & Hypertension and depression (19.7) & 12.9 \\
\hline 4 & Hypertension and malignancies (17.5) & 10.6 \\
\hline 5 & Depression and osteoarthritis & 8.7 \\
\hline \multicolumn{3}{|c|}{ GP settings } \\
\hline \multicolumn{3}{|c|}{ CMR Nijmegen } \\
\hline 1 & Hypertension (29.9) and osteoarthritis (27.2) & 9.1 \\
\hline 2 & Hypertension and obesity (18.2) & 8.8 \\
\hline 3 & Osteoarthritis and cataract (16.6) & 7.5 \\
\hline 4 & Hypertension and diabetes (14.6) & 7.4 \\
\hline 5 & $\begin{array}{l}\text { Hypertension and disorders of lipid } \\
\text { metabolism }(15.4)\end{array}$ & 7.2 \\
\hline \multicolumn{3}{|c|}{ RNGP } \\
\hline 1 & $\begin{array}{l}\text { Hypertension (31.1) and disorders of lipid } \\
\text { metabolism (12.5) }\end{array}$ & 6.4 \\
\hline 2 & Hypertension and diabetes (10.9) & 6.2 \\
\hline 3 & Hypertension and osteoarthritis (9.4) & 4.1 \\
\hline 4 & Hypertension and malignancies (8.4) & 3.4 \\
\hline 5 & Hypertension and arrhythmias (6.4) & 3.2 \\
\hline \multicolumn{3}{|c|}{ Hospital setting } \\
\hline \multicolumn{3}{|c|}{ LMR } \\
\hline 1 & $\begin{array}{l}\text { Ischemic beart disease (10.4) and } \\
\text { arthythmias (8.5) }\end{array}$ & 2.1 \\
\hline 2 & Arrhythmias and heart failure (5.0) & 1.8 \\
\hline 3 & Ischemic heart disease and heart failure & 1.5 \\
\hline 4 & Ischemic heart disease and diabetes (5.2) & 1.3 \\
\hline 5 & Ischemic heart disease and hypertension (3.8) & 1.1 \\
\hline \multicolumn{3}{|c|}{ Nursing home setting } \\
\hline \multicolumn{3}{|l|}{ RAI } \\
\hline 1 & Dementia (50.3) and hypertension (25.4) & 11.5 \\
\hline 2 & Dementia and stroke (30.8) & 11.5 \\
\hline 3 & Stroke and hypertension & 11.4 \\
\hline 4 & Dementia and osteoarthritis (20.2) & 10.0 \\
\hline 5 & Dementia and oerebral palsy (19.1) & 9.4 \\
\hline
\end{tabular}

Abbreviations: LASA, Longitudinal Aging Study Amsterdam; CMR Nijmegen, Continuous Morbidity Registry Nijmegen; RNUGP, Regional Network University General Practitioners Leiden and surroundings; LMR, Dutch National Medical Registry (Landelijke Medische Registratie); RAI, the VU University Medical Center Resident Assessment Instrument database.

The figures between brackets describe the prevalence of the individual diseases in percentages. 
Schram, M.T., Frijters, D., Lisdonk, E.H. van de, Ploemacher, J., Craen, A.J.M. de, Waal, M.W.M. de, Rooij, F.J. van, Heeringa, J., Hofman, A., Deeg, D.J.H., Schellevis, F.G. Setting and registry characteristics affect the prevalence and nature of multimorbidity in the elderly. Journal of Clinical Epidemiology: 2008, 61(11), 1104-1112

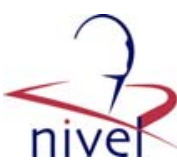

Table 3

Top five of comorbidities with diabetes in different settings

\begin{tabular}{|c|c|c|c|c|c|}
\hline Combination of diseases & $\begin{array}{l}\text { Prevalence } \\
(\%)\end{array}$ & Combination of diseases & $\begin{array}{l}\text { Prevalence } \\
\text { (\%) }\end{array}$ & Combination of diseases & $\begin{array}{l}\text { Prevalence } \\
\text { (\%) }\end{array}$ \\
\hline \multicolumn{6}{|l|}{ Population-based studies } \\
\hline \multicolumn{2}{|c|}{ Longitudinal Aging Study Amsterdam (LASA) } & \multicolumn{2}{|l|}{ Rotterdam Study } & \multicolumn{2}{|l|}{ Leiden 85-plus Study } \\
\hline $\begin{array}{l}1 \text { Diabetes (12.3) and hypertension } \\
\text { (37.1) }\end{array}$ & 7.6 & $\begin{array}{l}\text { Diabetes (17.7) and hypertension } \\
(61.8)\end{array}$ & 13.2 & $\begin{array}{l}\text { Diabetes (19.7) and hypertension } \\
(56.9)\end{array}$ & 8.6 \\
\hline 2 Diabetes and osteoarthritis (50.9) & 6.7 & Diabetes and atherosclerosis (63.3) & 12.0 & Diabetes and osteoarthritis (32.5) & 5.8 \\
\hline $\begin{array}{l}3 \text { Diabetes and ischemic heart disease } \\
\text { (29.6) }\end{array}$ & 5.1 & $\begin{array}{l}\text { Diabetes and hypertension and } \\
\text { atherosclerosis }\end{array}$ & 9.2 & Diabetes and depression (19.7) & 3.4 \\
\hline $\begin{array}{l}4 \text { Diabetes and peripheral artery } \\
\text { disease }(11.8)\end{array}$ & 2.6 & Diabetes and obesity (18.8) & 5.2 & Diabetes and malignancies (17.5) & 3.1 \\
\hline 5 Diabetes and malignancies (18.3) & 2.4 & $\begin{array}{l}\text { Diabetes and myocardial infarction } \\
(12.2)\end{array}$ & 2.8 & Diabetes and angina pectoris (18.4) & 2.9 \\
\hline \multicolumn{6}{|l|}{ GP registries } \\
\hline \multicolumn{2}{|l|}{ CMR Nijmegen } & \multicolumn{2}{|l|}{ RNUGP } & & \\
\hline $\begin{array}{l}1 \text { Diabetes (14.6) and hypertension } \\
\text { (29.9) }\end{array}$ & 7.4 & $\begin{array}{l}\text { Diabetes (10.9) and hypertension } \\
(31.1)\end{array}$ & 6.2 & & \\
\hline 2 Diabetes and obesity (18.2) & 6.4 & $\begin{array}{l}\text { Diabetes and disorders of lipid } \\
\text { metabolism }(12.5)\end{array}$ & 3.2 & & \\
\hline 3 Diabetes and cataract $(16.6)$ & 5.4 & Diabetes and arrhythmias (6.4) & 1.5 & & \\
\hline 4 Diabetes and osteoarthritis (27.2) & 5.0 & Diabetes and angina pectoris ( 6.2 ) & 1.4 & & \\
\hline $\begin{array}{l}5 \text { Diabetes and disorders of lipid } \\
\text { metabolism (15.4) }\end{array}$ & 4.3 & Diabetes and osteoarthritis (9.4) & 1.4 & & \\
\hline \multicolumn{2}{|l|}{$\begin{array}{l}\text { Hospital and nursing home setting } \\
\text { Hospital (LMR) }\end{array}$} & \multicolumn{2}{|l|}{ Nursing home (RAI) } & & \\
\hline $\begin{array}{l}1 \text { Diabetes (5.2) and ischemic heart } \\
\text { disease (10.4) }\end{array}$ & 1.3 & Diabetes (18.4) and dementia (50.3) & 7.6 & & \\
\hline 2 Diabetes and hypertension (3.8) & 0.9 & Diabetes and stroke (30.8) & 7.2 & & \\
\hline 3 Diabetes and arrhy thmias (8.5) & 0.9 & Diabetes and hypertension $(25.4)$ & 6.4 & & \\
\hline 4 Diabetes and heart failure $(5.0)$ & 0.8 & Diabetes and eye disease (19.2) & 3.8 & & \\
\hline 5 Diabetes and COPD (3.8) & 0.5 & $\begin{array}{l}\text { Diabetes and ischemic heart disease } \\
\text { (11.3) }\end{array}$ & 3.5 & & \\
\hline
\end{tabular}

Abbreviations: LASA, Longitudinal Aging Study Amsterdam; CMR Nijmegen, Continuous Morbidity Registry Nijmegen; RNUGP, Regional Network University General Practitioners Leiden and surroundings; LMR, Dutch National Medical Reg istry (Landelijke Medische Registratie); RAI, the VU University Medical Center Resident Assessment Instrument database.

The figures between brackets describe the prevalence of the individual diseases in percentages. 